\title{
Economic Integration of Selected Non-EU Countries in the EU Single Market
}

\author{
Armin Jans \& Björn Plaschnick *
}

\begin{abstract}
The degree of integration of an individual EU country in the European Union can be measured comprehensively and in a given time period with the EU index proposed by König and Ohr [4]. A modified EU index of 21 instead of originally 25 indicators allows examining the economic integration of non-EU member countries within the EU. For the first time, this is applied here to Norway, Turkey and the US and compared with the integration degree of the EU-25 countries and Switzerland. Except for Switzerland - showing a higher degree of integration than the EU average - the index values of the non-EU members are markedly below the EU average. In 2012 they can be often found at the last ranks of all 28 considered countries. Whilst the integration degree of Norway slightly fell from 2004 to 2012, the degree rose for the three other non-EU countries during this time period, least in Switzerland and most in Turkey. The cluster analysis confirms that the four non-EU countries are much more heterogeneous than the EU-25 members. Since 2004 this divergence increased for all non-EU member countries except for Turkey
\end{abstract}

Keywords - European Union, Regional economic integration, multivariate analysis

\section{Introduction}

Economic development of the last decades was characterized by the increasing economic interdependence of socio-economic different countries on a global scale. Due to the expected welfare gains there was wide political support for broad activities by international organizations (WTO, IMF, World Bank, BIS, OECD etc.), for bilateral treaties (e.g. double tax and investment treaties) and for multilateral free trade agreements (such as EFTA, NAFTA, AFTA etc.) up to common markets (EU, EEA, MERCOSUR) or the European economic and monetary union (Euro area). Whereas WTO and free trade agreements aim mainly at the liberalization and intensification of international trade and capital flows, common markets include also the free movement of persons and companies as well as common competition rules and bodies. Moreover the Euro area is marked by a common currency and an increased institutional and political integration, particularly by the European Central Bank.

In this context the question arises how to measure economic integration and interdependence of the member countries of any integration bloc (free trade agreement, customs union, common market etc.) in a comprehensive and adequate way. To our knowledge the EU Index proposed by König and Ohr [4] is the first indicator to meet this requirement. With this index König and Ohr measure the degree of European economic integration, i.e. the intensity of the "internal" mutual economic and institutional interdependence of the EU member countries. So far the EU Index was calculated for the members of the EU-15 and the period 1999-2010 [3, 4] as well as for the members of EU-25 and the years 2004-2012 [5]. With some minor modifications the EU Index can be adapted to measure the economic interdependence between non-member countries (such as accession candidates or important trade partners) and the European internal market. König/Ohr [6] showed this for the case of Switzerland.

In the following, the analysis will be broadened to include three more countries, namely the US, Norway - as the most important member of the European Economic Area (EEA) and Turkey, which forms a customs union with the EU and is an accession candidate for the EU as well. Institutionally the US is connected with the EU primarily by the WTO agreements. Negotiations about an ambitious free trade agreement between the US and the EU, the so-called Transatlantic Trade and Investment Partnership (TTIP), are currently ongoing.

The modified EU Index not only measures the economic integration of non-member countries in the EU single market but also allows estimating their prospective integration potential. Moreover index values of EU member states can be more easily and accurately interpreted. In particular it can be seen whether a given degree of EU-integration can be reached notwithstanding of an EU-membership.

The paper is organized as follows: Section II provides a short overview of the EU Index developed by König and Ohr. A description of the modified EU Index for Norway, Turkey and the US, the data and the general computational methods is given in section III. The results of our calculations of the respective sub-indices and the modified EU Index as well as a discussion of these results in the context of the Index values for Switzerland and the EU-25 is presented in section IV. Furthermore, we examine the development of the EU integration of these four countries with a cluster analysis. Finally, our main findings are summarized in section $\mathrm{V}$.

Armin Jans, Björn Plaschnick

Zurich University of Applied Sciences, School of Management Law, Center for Economic Policy Switzerland

\footnotetext{
${ }^{*}$ The authors wish to thank Jörg König for his helpful support particularly for data and reference values of the EU-25-countries and Switzerland as well as methodological comments.
} 


\section{Methodology of the EU Index}

The EU Index of König and Ohr [4, p. 1077-1079; 5] combines four dimensions of economic integration in the EU: the degree of integration in the EU single market, the degree of homogeneity as a measure for economic convergence, the extent of symmetry (synchronism) of business cycles and finally the degree of participation and conformity with the EU rules. Accordingly, the EU Index consists of four sub-indices which contain the following 25 indicators:

- Sub-index EU single market integration (8 indicators, combined weight 39.7\%): Exports to and imports from the EU of merchandise goods and services, foreign direct investment stocks in and from the EU, both in relation to GDP (= EU openness) and to total trade respectively to total FDI stock (= EU importance). Finally, two indicators for labor mobility, foreign workers from the EU in \% of all domestic workers (= EU openness) and in percent of all foreign workers (= EU importance).

- Sub-index EU homogeneity (7 indicators, combined weight 22.4\%): Real GDP per capita, purchasing power standards, labor costs per hour, long-term government bond yields, public debt ratios, implicit tax rate on private consumption and on capital.

- Sub-index EU symmetry (4 indicators, combined weight $15.6 \%$ ): Growth rate of real GDP, inflation rate, change in unemployment and government net borrowing.

- Sub-index EU conformity (6 indicators, combined weight 22.4\%): Membership in the Euro area, participation in the Schengen area, number of new reminders for compliance with EU rules issued by the EU Commission, convictions for non-compliance by the European Court of Justice in the domains of single market, "environment and consumer protection" and other sectors.

As the dimensions of the 25 indicators differ, aggregation requires normalization. König and Ohr's choice of a panel normalization allows for comparability over the whole period. Thus index values are exposed to a very limited sensitivity with respect to extreme values and year-to-year changes. The weights of the indicators (see above) and the sub-indices are not chosen a priori but calculated with an elaborate principal components analysis [3, p. 16-20 and p. 31-33].

König and Ohr did not calculate the EU Index for Luxembourg, as there were many extreme values in the indicators. Nevertheless, they include the data of Luxembourg in the EU-15- and EU-25-averages.

\section{The modified EU Index for Norway, Turkey and the US}

In this paper, we calculate the three sub-indices single market integration, homogeneity and symmetry as well as the modified EU Index - analogous to König and Ohr [6] - for the years 2004-2012. Thus, our results for Norway, Turkey and the USA and the results of König and Ohr for Switzerland and the EU-25 countries are directly comparable.

The calculations of the 21 indicators, the three sub-indices and the modified EU index follow the method used by König and $\mathrm{Ohr}[3,4,6]$. Since the conformity sub-index is not relevant for non-EU members, it is not considered in the modified EU Index. The weights of the remaining three subindices and 21 indicators are adjusted according to [6].

As far as possible, the data for the above mentioned 21 indicators were collected at the same sources used by König and Ohr [4], primarily Eurostat and OECD. Partially, data were completed from further sources, namely national statistical agencies. Time series from Eurostat, OECD or other sources being partially incomplete, plausible estimations or interpolations had to be made for missing years, notably for trade in services, labor force, implicit tax rates for consumption, particularly for the implicit capital tax rates in Turkey and the US and unemployment and government deficit ratios of Turkey. A detailed description of all data sources, weighting schemes and the calculation methods can be found in the appendix of our working paper.

Sometimes data from different sources were contradictory, for example data for trade in services by partner country from Eurostat and national statistical agencies. We try to circumvent this problem by using primarily - whenever possible - Eurostat data for the index calculation. The results were checked by alternative calculations with the national data. For example, in the sub-index single market integration, the indicators for trade in services with EU-25 were depending on the year - increased by 10-30\% for Norway, for the US they were lowered by $10-20 \%$. In the sub-index homogeneity two alternative specifications were used for the labor cost of Norway. The differences are low for 2004 and nearly $40 \%$ in 2012 . Due to the absence of data, the implicit capital tax rates for Turkey and the US had to be estimated. To test the sensitivity of the results, three alternative specifications were chosen for both countries.

In the EU index of König and Ohr, all indicators as well as the sub-indices and the EU index itself are normalized to a scale from 0 to 100 . The higher an indicator or index value, the more a country is integrated in the EU.

For the indicators in the sub-index homogeneity a value of zero is assigned to the EU member country showing the maximal divergence from the EU-mean (i.e. the relatively largest heterogeneity), whereas a value of 100 is attributed to a country with no deviation from the EU-mean (i.e. the largest possible homogeneity). As we apply the index to non-EU countries, the deviations of some of the indicators from the EU-mean may be larger than the maximal deviation within the EU. In this case an indicator becomes negative. This is the case for:

- Norway: real GDP per capita (2005-2012) and purchasing power standards (2011-2012);

- Turkey: long-term government bond yield (2004); 
- USA: real GDP per capita (2012) and implicit capital tax rate, intermediate variant (2004-2007) and maximal variant permanently (2004-2012).

In contrast to König and Ohr, who were not confronted with the problem, negative values for such indictors can arise in our paper.

\section{Results}

\section{A. State of formal integration}

All three examined countries are - like the EU-countries and Switzerland - members of the WTO, and thus participate in the GATT, GATS and TRIPS agreement. Except for Turkey they also take part in the following pluri-national agreements [8]:

- Duty-free trade in civil aircrafts and components of all kinds of sub-suppliers, including flight simulators;

- Public procurement of works, supplies and services of central, state and local governments as well as public utilities and public enterprises.

Three of the countries have concluded the following bilateral treaties with the EU:

- Norway is a member of the EEA and participates in the Schengen area, allowing full access to the EU single market.

- Turkey is connected to the EU by a customs union, under some provisions for agricultural products [1].

- The most important agreements of the US with the EU are the 'open sky' and a banana trade agreement [2]

Formally speaking, Norway is the country which is most integrated in the EU, followed - at a proper distance - by Turkey whose lead to the US is rather small. Switzerland has concluded over one hundred sectorial agreements with the EU which altogether come near to a membership to the EEA and hence to the degree of integration of Norway.

\section{B. Results for Norway, Turkey and the US}

At first the results for the three sub-indices are presented, followed by those for the modified total index.

\section{Sub-index EU single market integration}

This sub-index measures the relative integration in the EU single market, not absolute flows or stocks. Therefore a constant sub-index value means that the exchange relations with the EU remain proportionately unchanged. Fig. 1 shows that Norway was the most integrated country while the US was the least integrated into the EU single market in 20042012. The results obtained by using alternative national data for trade in services (labelled by ALT in Fig. 1) do not differ much from the results based on the data from Eurostat and hence do not modify this finding. Interestingly the index of Norway slightly rose in the chosen period, whereas the index for Turkey decreased slightly and the index for the US stagnated. So the economic integration of the US into the EU single market did not intensify, the integration of Turkey was even reduced in spite of the customs union and the current negotiations on EU entry.

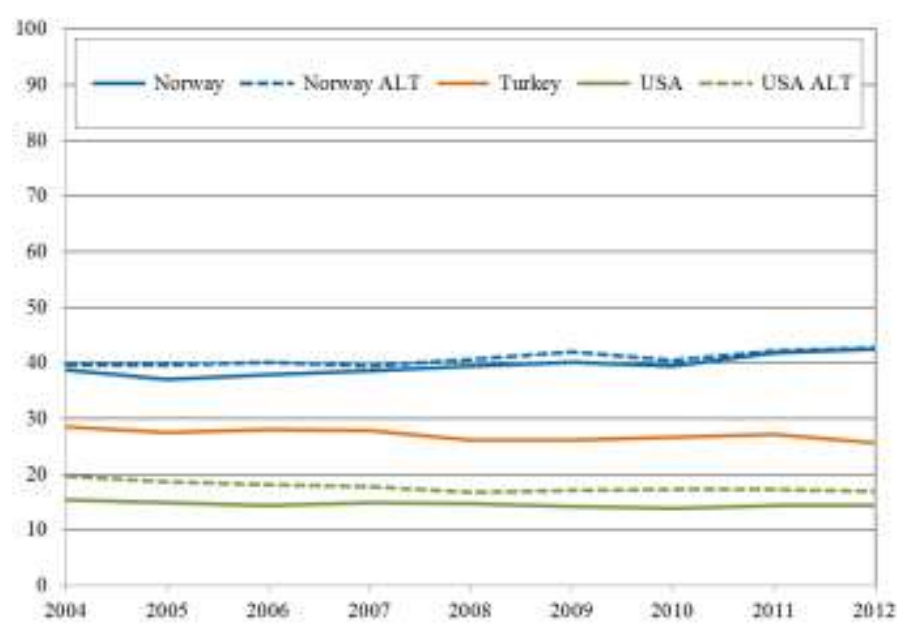

Figure 1. Sub-index EU single market integration for Norway, Turkey and the US (2004-2012)

\section{Sub-index EU homogeneity}

Fig. 2 shows a distinctly falling trend of this sub-index for Norway. The difference between the two specifications of the sub-index was due to increasing lower labor costs in the alternative (ALT) specification. The deviation rose over time and exceeded 12 index points in the last year (2012). The sudden fall in 2009-2012 - in our 'main' specification by more than half, in the alternative by more than one third - resulted to a large part from a markedly larger GDP growth rate and hence a higher increase of the purchasing power standard compared to the EU-25. To a lesser part the deviation was due to a falling government debt ratio.

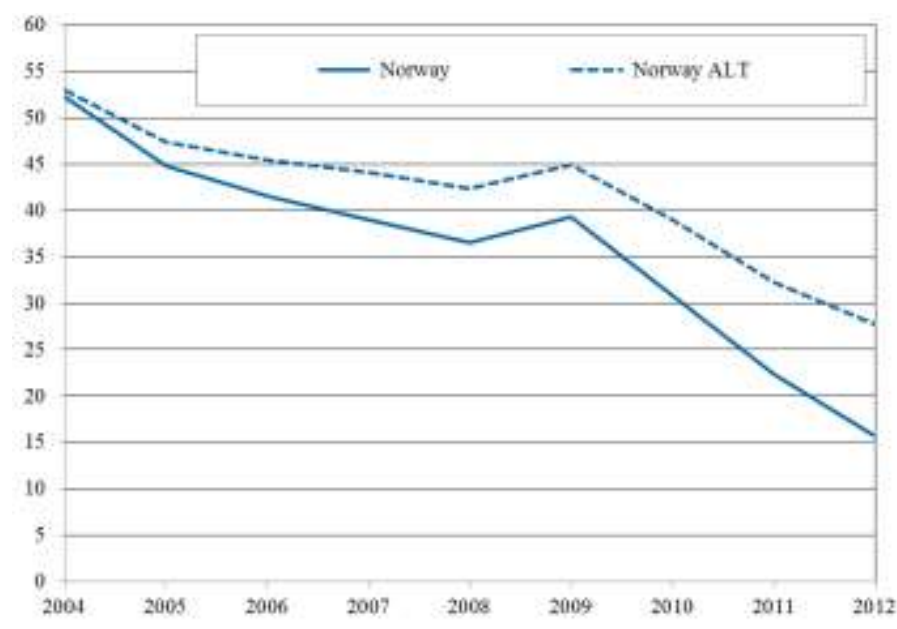

Figure 2. Sub-index EU homogeneity for Norway (2004-2012)

A more or less stagnating sub-index for Turkey can be seen in Fig. 3. The upward jump of two index points in 2010 was primarily due to smaller deviations of the purchasing power standard, the implicit consumption tax rate and the 
markedly larger growth rate of real GDP per capita compared to the mean of EU-25. The inclusion of a lower and an upper limit for the capital tax rate (labelled as MIN and MAX respectively) changes the result compared to the base case by less than one index point.

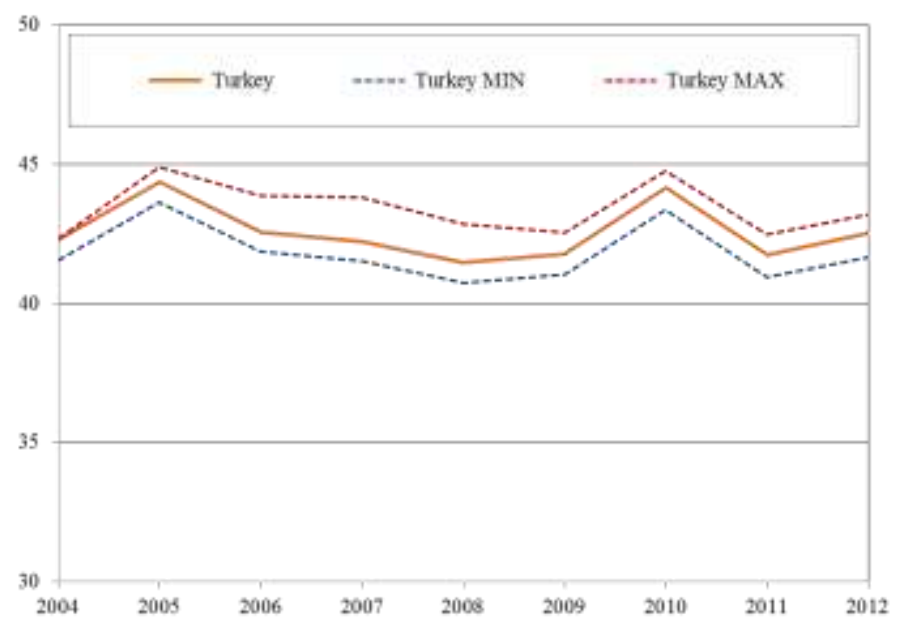

Figure 3. Sub-index EU homogeneity for Turkey (2004-2012)

For the US, the index followed a downward trend as it can be seen in Fig. 4. This trend emerged despite the sharp upward hike by more than six index points in 2009 which was mainly due to the development of two indicators: a larger decrease in real GDP per capita of the US relative to the EU-25 (the US being on a higher level than EU-25) and an increase in the purchasing power standard stemming from the nominal appreciation of the USD against the Euro, the US purchasing power being clearly below the EU-25 mean in 2008 and by and large at the same level in 2009. To a minor extent the increase in the consumption tax rate also contributed to the hike of the sub-index in 2009.

A lower and an upper limit for the capital tax rate (labelled as MIN and MAX respectively) lead to a deviation of the result from the base case by 1.5 index points only.

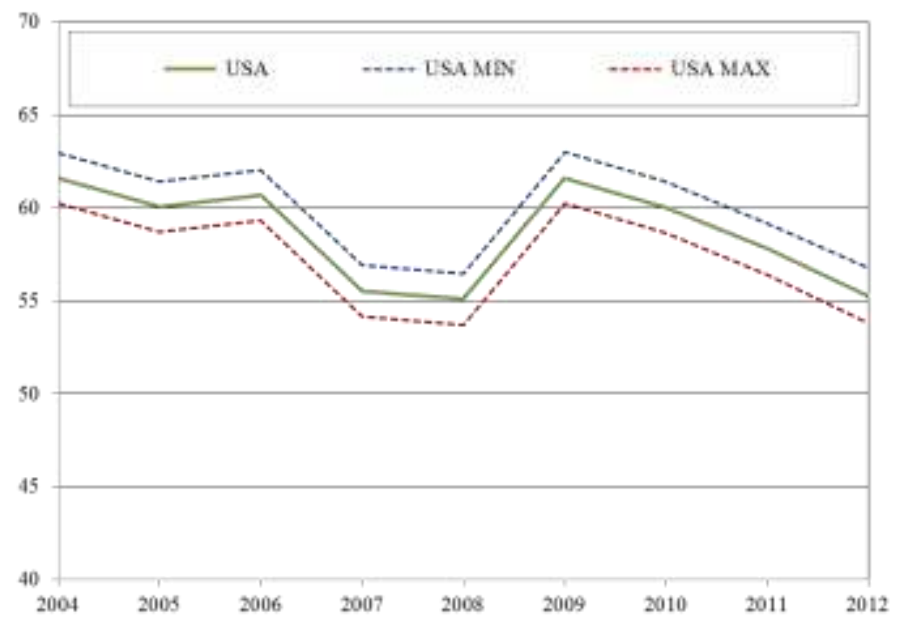

Figure 4. Sub-index EU homogeneity for the US (2004-2012)

\section{Sub-index EU symmetry}

Fig. 5 shows the degree of symmetry of the business cycles in the three examined countries with the EU-25 in the years 2004-2012.

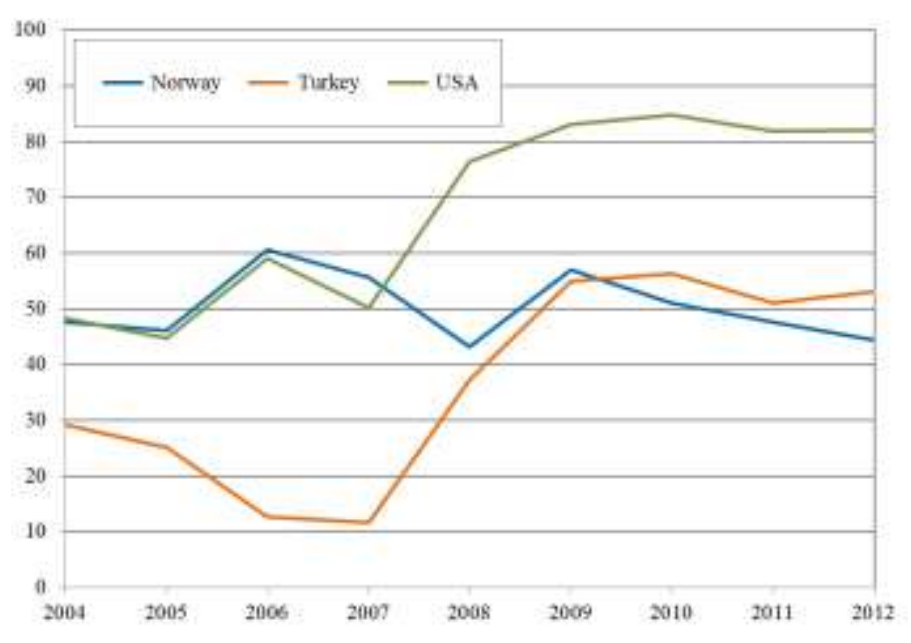

Figure 5. Sub-index EU symmetry for Norway, Turkey and the US (2004-2012)

The index value of Norway remained more or less constant over the whole period although the integration sub-index increased slightly. However the interdependence of the business cycles of Turkey and the US with the EU-25 rose strongly from 2007 onwards. This was likely due to the aggravating effects of the global financial crisis since 20072008 which affected all of these countries very much. The decrease of the Norwegian index since 2009 is explainable by a much milder recession than in the EU and subsequently by a higher growth rate of real GDP, a different inflation rate and a markedly slower increase in the unemployment rate remaining on a very low level. Moreover Norway experienced a government budget surplus of $10 \%$ of the GDP and more since 2004.

\section{Comparison of the modified EU Index for Norway, Turkey and the US with the EU-25 and Switzerland}

In the following we compare the calculated index values for Norway, Turkey and the US with those of the EU-15 and the EU-25 (averages weighted with population) and of Switzerland published by König and Ohr. Moreover a shaded area in the figures indicates the range of the indices of all countries of EU-25 so that it becomes clear whether the indices of the non-EU members are closer to the minimal or the maximal EU value.

Starting with the sub-index EU single market integration in Figure 6, it is remarkable that Switzerland was the most integrated of the four non-EU member countries over the entire time period, with an increasing trend and close to the maximum value of EU-25. Norway exhibited a slightly rising trend being not much over the average of EU-15 and EU-25. In comparison, the index for Turkey and the US stagnated 
significantly below the EU average, Turkey lying above and the US below the minimum value of EU-25.

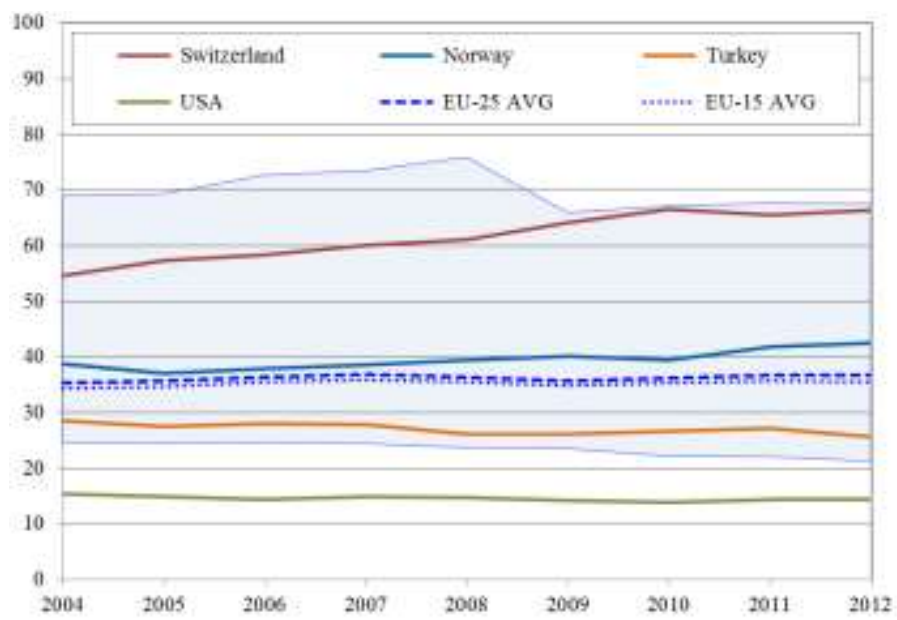

Figure 6. Comparison of the sub-index EU single market integration (2004-2012)

As it can be seen in Figure 7, the sub-index homogeneity of none of the four non-EU members reached the EU average over the entire time period. The US was closest to that average while Norway was furthest from it showing a falling trend like Switzerland. From 2009 onwards the index for all non-EU countries (except for Turkey) decreased thus raising the distance from the EU-25 average. This was mostly due to higher growth rates of real GDP compared to the EU-25. From 2010 onward, Norway fell even below the minimum value of EU-25 with an increasing deviation from the average.

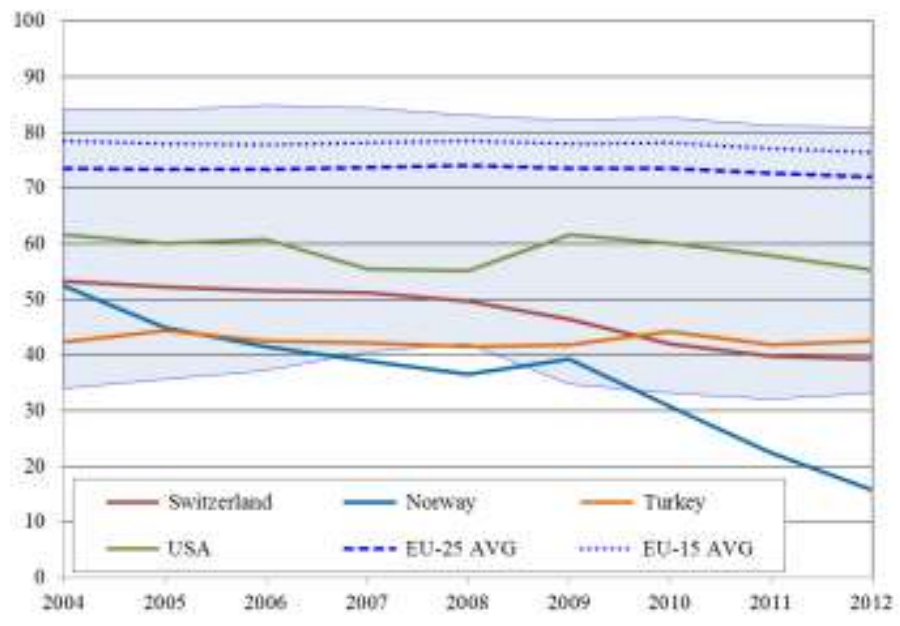

Figure 7. Comparison of the sub-index EU homogeneity (2004-2012)

Figure 8 shows that the symmetry of business cycles rose within the EU-15 and the EU-25 in the period 2004-2009 and remained more or less constant afterwards. Out of the four non-EU countries, only the US was following the EU average. In contrast, Norway and Switzerland were progressively below the EU averages since 2007/2008 whilst they exceeded these averages until 2007/2008. In the last three years, Norway sank even below the EU-25 minimum. Starting from a low level the index of Turkey steadily increased and ended between Norway and Switzerland in 2012. All four non-EU countries showed index values above the EU minimum, the gap between Norway and Switzerland and this minimum decreased substantially from 2004 to 2012.

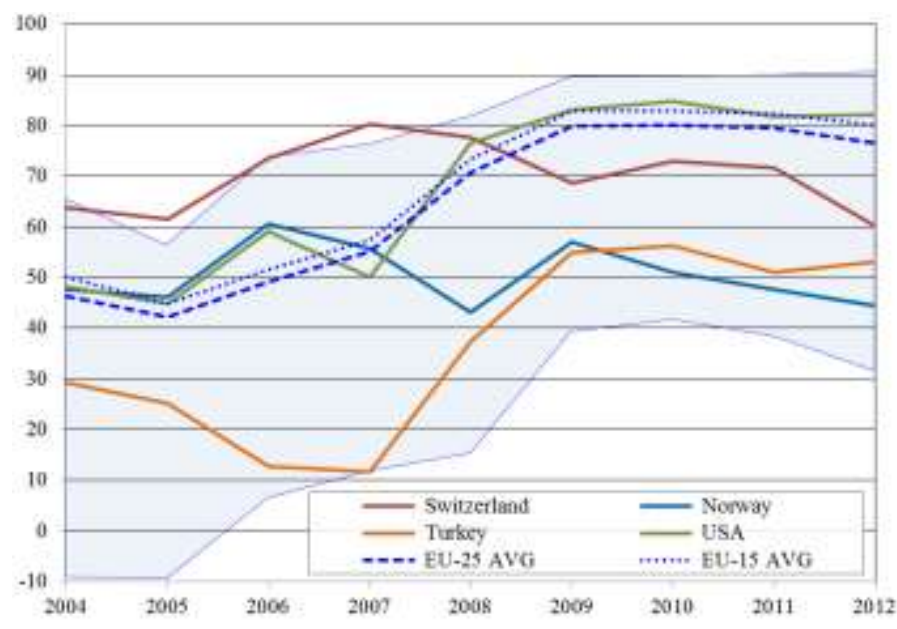

Figure 8. Comparison of the sub-index EU symmetry (2004-2012)

The three sub-indices for integration, homogeneity and symmetry are aggregated to the modified (total) EU Index using the weights of the principal components analysis. Figure 9 shows that Switzerland exceeded the averages for the EU-15 and the EU-25 during the whole period, yet the distance to the average decreased over time. In contrast, the index for the other non-EU countries is markedly below the EU averages reaching the EU-25 minimum value in 2012.

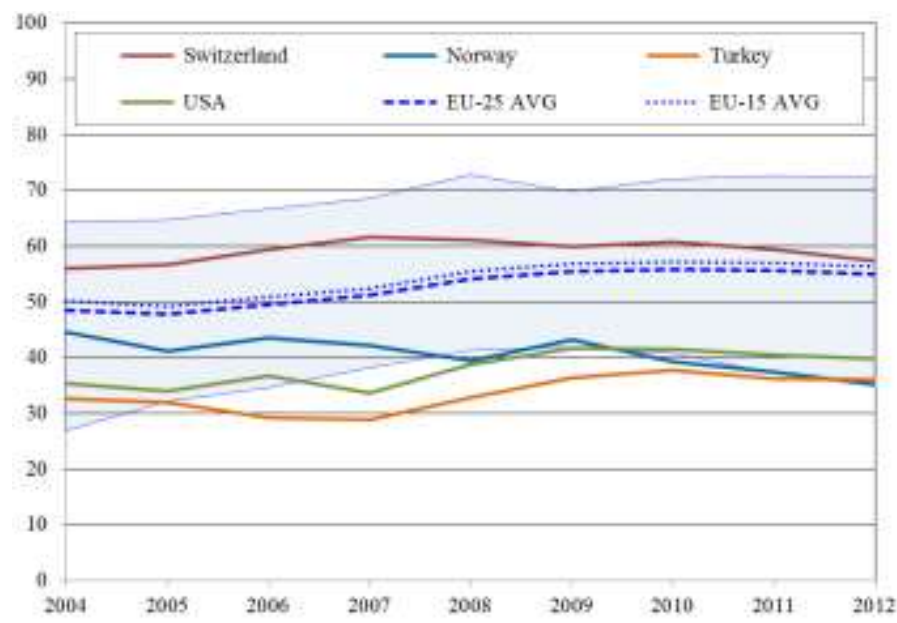

Figure 9. Comparison of the modified EU Index (2004-2012)

\section{Cluster Analysis}

The data for the 21 unweighted indicators of the modified EU Index for all 28 countries are further examined by a hierarchical cluster analysis. The resulting dendograms for 2004 and 2012 are presented in Fig. 10 and Fig. 11. The squared Euclidian distance indicates the variation of the EU integration among the countries. The dendrograms do not show any bilateral networks but rather similarities of the integration patterns. 


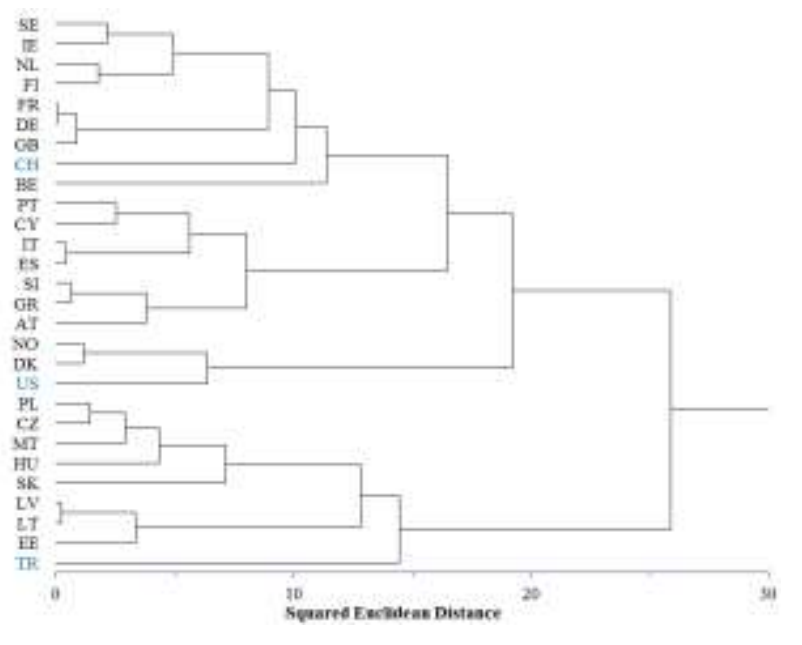

Figure 10. Dendrogram in 2004

- Five country clusters can be identified in 2004 according to a relatively small "within" and an increasing "between" heterogeneity (measured by the squared Euclidean distance):

- A first group of the three largest EU economies Germany, France and the UK, and, at a larger distance (i.e. rising heterogeneity), a series of northern and western European countries including Switzerland;

- A larger group of mainly southern European countries such as Italy, Spain, Portugal, Cyprus, Greece, plus Austria and Slovenia;

- A small group containing Norway, Denmark and the US;

- A cluster of Central and Eastern European accession countries led by Poland and the Czech Republic and followed by Hungary, Slovakia, Malta and a subcluster of the Baltic States.

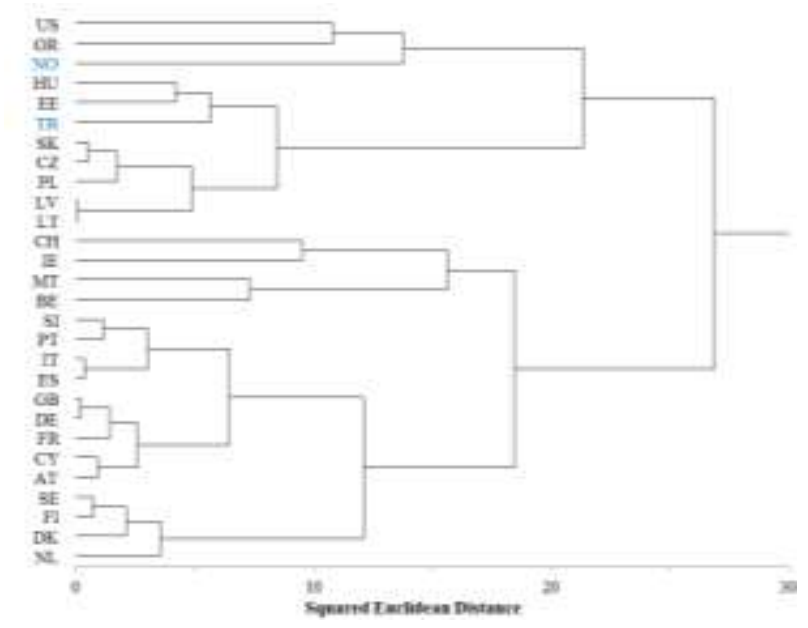

Figure 11. Dendrogram in 2012

As heterogeneity among the countries correlates strongly with geographical proximity (except for the US), the visible structures are mostly characterized by a regional pattern. Among the non-EU countries Switzerland shows the least heterogeneity being connected with the large European economies in the first cluster even ahead of Belgium. Norway and the US follow at a large distance being close to the southern European countries and ahead of the EU accession candidates of central and Eastern Europe. Turkey is most heterogeneous among all non-EU members which are very heterogeneous among themselves in comparison to the EU-25 member countries.

Comparing the dendrograms in Fig. 10 and Fig. 11, it can be seen that larger regional clusters mostly disintegrated in the period from 2004 to 2012 as the regional disparities rose seemingly. Certainly there is still a European "core-cluster" with Germany, France and the UK and an approaching group out of the largest southern European countries. On the other hand, heterogeneity between this "core-cluster" and the northern European countries increased. A differing development course of neighbor countries can be seen when comparing Cyprus with Greece or Ireland with the UK. In general, the EU-25 countries did not become more homogeneous or more heterogeneous from 2004 to 2012, they rather moved in different directions. A similar picture can be seen for the non-EU members: since 2004 heterogeneity increased compared to the EU-25 except for Turkey. In particular Switzerland diverted from the members of the "core cluster" and does not belong to them anymore. To a lower extent the heterogeneity of Norway and the US also rose. As the heterogeneity of Turkey slightly decreased, these three countries are on a similar level in 2012. All in all, this is widely congruent with the development of the index values of these countries discussed in Sections IV.B und IV.C.

\section{E. Summary}

Originally, the EU Index of König and Ohr measures the economic integration of different EU member countries into the EU. The authors extended the scope of application to nonEU member countries by calculating a modified EU Index for Switzerland. We now follow with the results for three further non-EU countries, namely Norway, Turkey and the US.

The modified EU Index for Switzerland exceeds the averages for EU-15 and EU-25 during the period 2004-2012. In comparison, the three other non-EU countries are markedly below the averages and quite close together in 2012. Norway shows a slightly decreasing trend in 2004-2012 that is in contrast to the other three non-EU countries.

Among the sub-indices for the average of EU-25, the value of the sub-index for homogeneity was the highest in 2004 while the value for integration was the lowest. Except for Switzerland, the non-EU countries showed the same pattern of development. Until 2012 the order of the sub-indices for EU25 had changed, at the top was now the sub-index symmetry whereas the sub-index integration remained at the rear. This pattern was also observable for Turkey and the US, but Norway and Switzerland clearly differ from that.

The integration pattern of the different countries was further examined with a cluster analysis of the 21 unweighted 
indicators. A core group of Germany, the UK and France showed the lowest heterogeneity in 2004 as well as in 2012. In general, the EU countries moved in different directions from 2004 to 2012. A similar picture can be seen for the markedly more heterogeneous non-EU members: since 2004 heterogeneity rose in comparison to the EU-25 countries except for Turkey.

The analysis also showed that a non-EU member can show a higher degree of EU integration than the average of the EU countries. This is the case for the modified EU index of Switzerland, for the sub-index single market integration of Switzerland and Norway, and the sub-index symmetry of the US. Switzerland deserves particular emphasis, being second only to Belgium for the sub-index single market integration, ahead of all other countries for the sub-index symmetry in 2005 and 2007 and - for the modified EU index - beginning as second in 2004 and ending as seventh in 2012. But generally the index values of the non-EU members are markedly below the EU average, in 2012 they can be mostly found at the bottom of the 28 examined countries (rank 2328).

Altogether the modified EU index allows measuring the degree of interdependence of any country with the EU no matter whether the country is a member of the EU or not. With adequate modifications of the weights the index is also suited to measure the integration of countries in other integration blocs (e.g. NAFTA, Mercosur and AFTA).

\section{References}

[1] European Union, "Treaties Office Database - List of treaties by country: Turkey", http://ec.europa.eu/world/agreements/searchByCountryAndCo ntinent.do?countryId=5745\&countryName=Turkey, 12.12.2014.

[2] European Union, "Treaties Office Database - List of treaties by country: United States of America", http://ec.europa.eu/world/agreements/ searchByCountryAndContinent.do? countryId=6063\&countryName=Uni ted States of America, 13.12.2014.

[3] J. König and R. Ohr, ,,Messung ökonomischer Integration in der Europäischen Union - Entwicklung eines EU-Integrationsindexes“, Centrum für Europa-, Governance- und Entwicklungsforschung Georg-AugustUniversität Göttingen, http://wwwuser.gwdg.de/ cege/Diskussionspa piere/135, 2012.

[4] J. König and R. Ohr, "Different Efforts in European Economic Integration: Implications of the EU Index", Journal of Common Market Studies, vol. 51, pp. 1074-1090, June 2013.

[5] J. König and R. Ohr, "EU-25-Index“, http://www.eu-index.unigoettingen.de/?page_id=221.

[6] J. König and R. Ohr, "EU-Schweiz-Index“, http://www.eu-index.unigoettingen.de/?page_id=612.

[7] Piketty, Thomas, "Capital in the twenty-first century", Cambridge, MA, Harvard University Press, 2014.

[8] World Trade Organization, "Understanding the WTO - Plurilaterals: of minority interest”, http://www.wto.org/english/thewto_e/whatis_e/tif_e/ agrm10_e.htm\#civil, 13.12.2014. 
Proc. of the Second Intl. Conf. on Advances in Management, Economics and Social Science - MES 2015 Copyright (C) Institute of Research Engineers and Doctors, USA .All rights reserved.

ISBN: 978-1-63248-046-0 doi: 10.15224/ 978-1-63248-046-0-92

\section{Appendices}

Index values 2004 - 2012 for the sub-indices and the modified EU Index

\begin{tabular}{|c|c|c|c|c|c|c|c|c|c|}
\hline \multirow{8}{*}{ 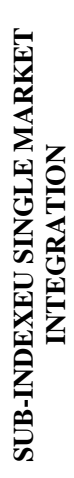 } & Year & Switzerland & Norway & Turkey & USA & EU-25 AVG & EU-25 MIN & EU-25 MAX & EU-15 AVG \\
\hline & 2004 & 54.54 & 38.83 & 28.56 & 15.37 & 35.33 & 24.93 & 69.04 & 34.41 \\
\hline & 2005 & 57.25 & 37.00 & 27.58 & 14.88 & 35.61 & 24.83 & 69.37 & 34.70 \\
\hline & 2007 & 60.12 & 38.58 & 27.87 & 14.85 & 36.90 & 24.80 & 73.48 & 35.92 \\
\hline & 2008 & 61.09 & 39.50 & 26.14 & 14.66 & 36.45 & 24.05 & 75.89 & 35.52 \\
\hline & 2010 & 66.49 & 39.43 & 26.67 & 13.93 & 36.21 & 22.56 & 67.20 & 35.27 \\
\hline & 2011 & 65.60 & 41.89 & 27.23 & 14.43 & 36.76 & 22.47 & 67.71 & 35.68 \\
\hline & 2012 & 66.30 & 42.53 & 25.65 & 14.33 & 36.75 & 21.68 & 67.58 & 35.56 \\
\hline
\end{tabular}

\begin{tabular}{|c|c|c|c|c|c|c|c|c|c|}
\hline \multirow{10}{*}{ 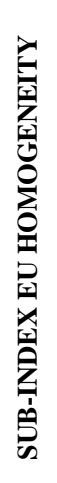 } & & Switzerland & Norway & Turkey & USA & EU-25 AVG & EU-25 MIN & EU-25 MAX & EU-15 AVG \\
\hline & 2004 & 53.18 & 52.32 & 42.27 & 61.61 & 73.51 & 34.26 & 84.13 & 78.40 \\
\hline & 2005 & 52.19 & 44.81 & 44.35 & 60.07 & 73.39 & 35.93 & 83.98 & 77.95 \\
\hline & 2006 & 51.51 & 41.53 & 42.57 & 60.68 & 73.34 & 37.44 & 84.79 & 77.80 \\
\hline & 2007 & 51.14 & 38.99 & 42.23 & 55.53 & 73.68 & 40.77 & 84.33 & 78.20 \\
\hline & 2008 & 49.59 & 36.59 & 41.45 & 55.08 & 74.10 & 42.31 & 83.05 & 78.51 \\
\hline & 2009 & 46.46 & 39.33 & 41.77 & 61.61 & 73.55 & 35.07 & 82.10 & 77.95 \\
\hline & 2010 & 42.04 & 30.82 & 44.15 & 60.02 & 73.59 & 33.44 & 82.59 & 78.15 \\
\hline & 2011 & 39.82 & 22.36 & 41.74 & 57.80 & 72.69 & 32.37 & 81.18 & 77.11 \\
\hline & 2012 & 39.31 & 15.73 & 42.51 & 55.28 & 72.01 & 33.45 & 80.86 & 76.38 \\
\hline
\end{tabular}

\begin{tabular}{|c|c|c|c|c|c|c|c|c|c|}
\hline \multirow{10}{*}{ 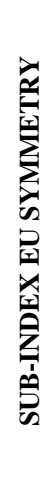 } & & Switzerland & Norway & Turkey & USA & EU-25 AVG & EU-25 MIN & EU-25 MAX & EU-15 AVG \\
\hline & 2004 & 63.78 & 47.68 & 29.27 & 48.24 & 46.38 & -8.41 & 65.60 & 50.13 \\
\hline & 2005 & 61.43 & 46.15 & 25.03 & 44.75 & 42.19 & -8.87 & 56.51 & 44.91 \\
\hline & 2006 & 73.58 & 60.51 & 12.69 & 59.01 & 49.09 & 7.02 & 73.85 & 51.64 \\
\hline & 2007 & 80.32 & 55.63 & 11.63 & 50.15 & 55.21 & 12.25 & 76.29 & 57.32 \\
\hline & 2008 & 77.65 & 43.21 & 37.28 & 76.43 & 70.63 & 15.76 & 81.82 & 73.35 \\
\hline & 2009 & 68.64 & 57.05 & 54.89 & 83.10 & 79.86 & 39.64 & 89.62 & 82.79 \\
\hline & 2010 & 73.01 & 51.08 & 56.25 & 84.72 & 80.13 & 41.94 & 89.72 & 82.84 \\
\hline & 2011 & 71.64 & 47.54 & 50.99 & 81.81 & 79.53 & 38.71 & 89.86 & 82.38 \\
\hline & 2012 & 60.13 & 44.42 & 53.01 & 82.12 & 76.51 & 31.84 & 90.52 & 80.14 \\
\hline
\end{tabular}

\begin{tabular}{|c|c|c|c|c|c|c|c|c|c|}
\hline \multirow{7}{*}{ 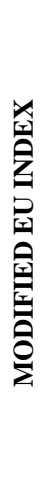 } & & Switzerland & Norway & Turkey & USA & EU-25 AVG & EU-25 MIN & EU-25 MAX & EU-15 AVG \\
\hline & 2005 & 56.63 & 41.09 & 31.93 & 33.96 & 47.81 & 32.40 & 64.76 & 49.20 \\
\hline & 2007 & 61.58 & 42.11 & 28.79 & 33.71 & 51.17 & 38.42 & 68.58 & 52.39 \\
\hline & 2008 & 61.09 & 39.40 & 32.81 & 38.74 & 54.15 & 41.51 & 72.81 & 55.49 \\
\hline & 2010 & 60.75 & 39.26 & 37.66 & 41.46 & 55.79 & 41.04 & 72.09 & 57.16 \\
\hline & 2011 & 59.38 & 37.36 & 36.19 & 40.48 & 55.69 & 37.42 & 72.59 & 56.98 \\
\hline & 2012 & 57.29 & 35.14 & 36.01 & 39.76 & 54.88 & 35.20 & 72.29 & 56.26 \\
\hline
\end{tabular}


Proc. of the Second Intl. Conf. on Advances in Management, Economics and Social Science - MES 2015 Copyright (C) Institute of Research Engineers and Doctors, USA .All rights reserved.

ISBN: 978-1-63248-046-0 doi: 10.15224/ 978-1-63248-046-0-92

Indicators and sub-indices in the modified EU Index and their respective weights according to König/Ohr [6]

Sub-index / Indicator

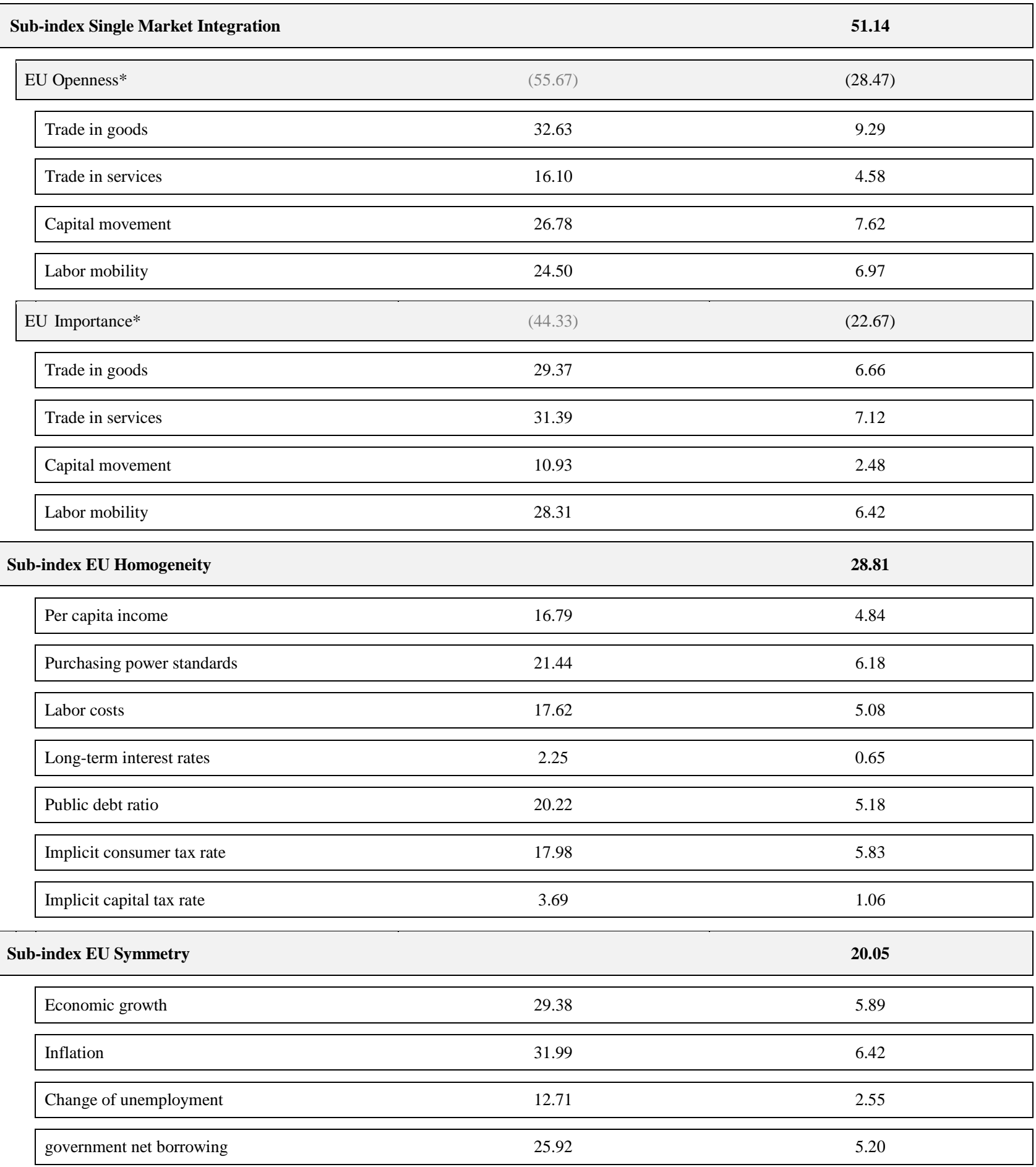

* The weights in parentheses are the weights of the sub-indices EU openness and EU importance in the sub-index EU single market respectively the modified EU Index. The sum of weights deviates from 100 due to rounding differences.

Additional supporting information such as a detailed description of the computational methods and the data sources will be soon available in the online version of this article at the webpage of the SML Working Paper Series at http://sml.zhaw.ch/en/management/about-us/publications/sml-working-papers.html. 